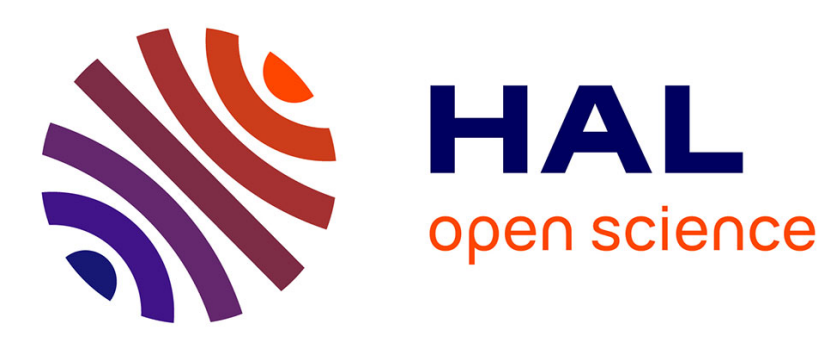

\title{
Instability of dilute poly(ethylene-oxide) solutions
}

\author{
Y. Layec, M.-N. Layec-Raphalen
}

\section{To cite this version:}

Y. Layec, M.-N. Layec-Raphalen. Instability of dilute poly(ethylene-oxide) solutions. Journal de Physique Lettres, 1983, 44 (3), pp.121-128. 10.1051/jphyslet:01983004403012100 . jpa-00232151

\section{HAL Id: jpa-00232151 https://hal.science/jpa-00232151}

Submitted on 1 Jan 1983

HAL is a multi-disciplinary open access archive for the deposit and dissemination of scientific research documents, whether they are published or not. The documents may come from teaching and research institutions in France or abroad, or from public or private research centers.
L'archive ouverte pluridisciplinaire HAL, est destinée au dépôt et à la diffusion de documents scientifiques de niveau recherche, publiés ou non, émanant des établissements d'enseignement et de recherche français ou étrangers, des laboratoires publics ou privés. 
Classification

Physics Abstracts

36.20

\title{
Instability of dilute poly(ethylene-oxide) solutions
}

\author{
Y. Layec and M.-N. Layec-Raphalen \\ Laboratoire d'Hydrodynamique Moléculaire, Faculté des Sciences, \\ 6, avenue Victor Le Gorgeu, 29283 Brest Cedex, France
}

(Reçu le 13 septembre 1982, révisé le 16 novembre, accepté le 13 décembre 1982)

\begin{abstract}
Résumé. - Nous avons étudié par diffusion de la lumière des solutions de poly(oxyéthylène) dans le méthanol, l'eau pure et un mélange eau-isopropanol. En solution alcoolique, le POE est moléculairement dispersé et ne présente pas d'anomalie de comportement. Dans l'eau, le polymère semble être sous une forme agrégée évoluant avec le temps. Aux grandes valeurs du vecteur de diffusion $\mathbf{K}$, la fréquence caractéristique est proportionnelle à $K^{w}$ avec $w=2,95$, valeur très proche de la valeur 3 espérée théoriquement. Aux faibles valeurs de $\mathbf{K}$, on obtient un coefficient de diffusion évoluant avec le temps. Cette évolution s'interprète comme un désenchevêtrement des agrégats initiaux.
\end{abstract}

\begin{abstract}
Using photon correlation spectroscopy we studied dilute solutions of poly(ethyleneoxide) in solvents such as methanol, pure water, or, a water isopropanol mixture. In alcohol the polymer is molecularly dispersed and the solution is stable over a period of time. On the other hand, aggregates seem to be present in water and to be time-dependent. For high values of the scattering wave vector $\mathbf{K}$ the inverse relaxation time is proportional to $K^{w}$ where $w=2.95$ which is in good agreement with the expected theoretical value for internal motions of the coil. At the lower $\mathbf{K}$ values the diffusion coefficient is found to evolve with time. This evolution is interpreted as a disentanglement of the initial aggregates.
\end{abstract}

1. Introduction. - Some large flexible macromolecules have a drag reducing property. Poly(ethylene-oxide) (PEO) is one such water-soluble polymer largely used in turbulent flows [1-5]. The efficiency in drag-reduction is enhanced by its propensity for forming aggregates in solution even at very low concentrations [6,7]. This property is solvent dependent but, as far as we know, no attempt to link this dependence to the quality of the solvent has been made. In solvents such as methanol or dioxane, PEO would be molecularly dispersed [8] while aggregation has been confirmed by light scattering [8-10] electronic microscopy, viscometry [10], or spectroscopic techniques [11] in solvents such as benzene, dimethylformamide or chloroform. Moreover the situation in pure water could be further complicated by the formation of complex structures through hydrogen bounding and the formation of trihydrates due to the chemical nature of the chain $[11,12]$.

PEO solutions show a decreasing efficiency in drag-reduction with ageing. Some authors [13-16] think this is more likely to be due to a physical mechanism like dissociation or disentanglement of aggregates than to a chemical degradation of the chain. PEO is a very efficient 
agent when freshly put into solution and loses this property as the solution becomes more and more « homogeneous " $[17,18]$.

In this paper we are reporting results of photon correlation spectroscopy experiments on dilute PEO solutions over periods as long as two months. We have used a PEO sample in pure water, pure methanol and an isopropanol-water mixture. The evolution of the deduced relaxation time allows us to decide if the polymer is molecularly dispersed or not, and to have an indication of the real effect of isopropanol on the polymer in the water solution.

2. Experimental part. - 2.1 SAMPLE AND sOlutions. - We used a commercial PEO with a molecular weight $M_{\mathrm{w}}=660000$, a polydispersity $M_{\mathrm{w}} / M_{\mathrm{n}}=1.10$ as given by the manufacturer together with some other characteristics (Table I).

Water was twice distilled and deionized. Alcohols were of spectroscopic grade and used without further purification. The isopropanol was mixed with water before being added to the polymer. All the solvents were filtered through $0.2 \mu$ membranes directly into the cell under a dust free bench

Table I. - Molecular characteristics of the PEO sample SE 70 as given by Toyo Soda Manufacturing Co, Ltd. Tokyo, Japan.

\begin{tabular}{|c|c|c|c|c|}
\hline Type & $M_{\mathrm{w}} \times 10^{-5}\left({ }^{a}\right)$ & $M_{\mathrm{v}} \times 10^{-5}\left({ }^{b}\right)$ & $M_{\mathrm{w}} \times 10^{-5}\left({ }^{c}\right)$ & $M_{\mathrm{w}} / M_{\mathrm{n}}\left({ }^{c}\right)$ \\
\hline SE 70 & 6.61 & 7.35 & 7.23 & 1.10 \\
\hline
\end{tabular}

$\left({ }^{a}\right)$ Low angle light scattering $\left(\theta=5^{\circ}\right)$ in water at $25^{\circ} \mathrm{C}$.

${ }^{(b)}$ Obtained through the equation [32] $[\eta]=3.97 \times 10^{-2} M_{\mathrm{w}}^{0.686} \mathrm{~cm}^{3} / \mathrm{g},[\eta]$ being measured in benzene at $25^{\circ} \mathrm{C}$ with a capillary viscometer.

(c) These two last values are obtained by GPC in water at $25^{\circ} \mathrm{C}$.

All experiments were performed at $21.5^{\circ} \mathrm{C}$.

As methanol is a bad solvent for PEO at this temperature (the polymer crystallizes near $19^{\circ} \mathrm{C}$ ), the solutions in this solvent were prepared at $25^{\circ} \mathrm{C}$ and then slowly cooled to $21.5^{\circ} \mathrm{C}$.

Solutions in water and in the water-isopropanol (90/10) mixture were clear within 24 hours.

We took great care to avoid degradations of any sort, either mechanical, chemical or bacterial. Prepared with filtered solvents and pure polymer, the solutions were not filtered and were gently shaken only when necessary. They were kept in a dark room at a constant temperature. The absence of bacteria in water solutions was verified.

All concentrations were chosen so that we could always consider the solutions as dilute. In such a solution where interactions can be neglected, macromolecules behave as independent coils. The radius of gyration is then related to the molecular weight by $R_{\mathrm{G}} \sim M^{v}, v$ being an exponent dependent on the quality of the solvent lying between 0.5 in a $\theta$-solvent and 0.6 in a good solvent. The concentration at which molecules begin to interact is $C^{+} \sim \frac{M}{N_{\mathrm{A}} R_{\mathrm{G}}^{3}}, N_{\mathrm{A}}$ being Avogadro's number. As the proportionality constant and $R_{\mathrm{G}}$ are dependent on experimental parameters such as the quality of the solvent, interactions or the polydispersity, this concentration has to be deduced from experimental results. So we used the estimate of Simha [19] where the concentration corresponding to incipient overlap of spherical coils is $c_{\mathrm{s}}^{+} \simeq 1 /[\eta]$ where $[\eta]$ is the intrinsic viscosity of the polymer. All our concentrations are of the order of $c_{\mathrm{s}}^{+} / 10$. 
2.2 The EXPERIMENTAL TECHNIQUe AND DATA ANALYSIS. - Quasi-elastic light scattering experiments were performed in the homodyne mode, using a photon correlation spectrometer, described in full detail elsewhere [20]. The single clipped photocount autocorrelation function of the scattered light $C(\mathbf{K}, t)$ was obtained using a 50 ns ATNE correlator. This unit has 104 channels, the last four ones being delayed by $96 \Delta t$, thus allowing a good determination of the baseline.

If the diffused electric field is Gaussian $C(\mathbf{K}, t)$ is related to the dynamical structure factor of the polymer in solution by

$$
C(\mathbf{K}, t)=a|S(\mathbf{K}, t)|^{2}+B,
$$

where $a$ and $B$ are parameters which include experimental features and $\mathbf{K}$ is the scattering wave vector $|\mathbf{K}|=K=\frac{4 \pi n}{\lambda_{0}} \sin \frac{\theta}{2}$, with $n$ being the refractive index of the solvent, $\lambda_{0}$ the wavelength of the incident light and $\theta$ the scattering angle.

If the sample is monodisperse and $c \ll c^{+}$, the dynamical structure factor is $S(\mathbf{K}, t)=$ $S(\mathbf{K}, 0) \exp (-\Gamma(K) t)$ and

$$
C(\mathbf{K}, t)=A \exp (-2 \Gamma t)+B
$$

where $\Gamma(K)=\tau^{-1}$ is the characteristic frequency related to the translation diffusion coefficient through $[21,22]$

$$
\Gamma(K)=D K^{2} f\left(K R_{\mathrm{G}}\right)
$$

$f$ is a dimensionless function of $x=K R_{\mathrm{G}} ; D$ is related to the hydrodynamic radius $R_{\mathrm{H}}$ through the Stokes-Einstein relation for a sphere

$$
D=\frac{k_{\mathrm{B}} T}{6 \pi \eta_{0} R_{\mathrm{H}}}
$$

$k_{\mathrm{B}}$ is the Boltzmann constant, $\eta_{0}$ the viscosity of the solvent at the absolute temperature $T$.

If $x<1$, the structure factor is dominated by the translational motion of well separated chains, $\tau \sim R_{\mathrm{H}}, f(x) \simeq 1$ and

$$
\Gamma=D K^{2} \text {. }
$$

If $x>1$, local properties are observed and the relaxation time is expected to be independent of $M$ and $R_{\mathrm{G}}$ (or $R_{\mathrm{H}}$ ). Then the relation (3) gives us

$$
\Gamma \sim K^{3} \text {. }
$$

Now, if the sample in solution is polydispersed (molecular polydispersity or aggregates) then the dynamical structure factor and therefore the autocorrelation function are no longer single exponentials but

$$
S(\mathbf{K}, t)=S(\mathbf{K}, 0) \int \exp (-\Gamma t) G(\Gamma) \mathrm{d} \Gamma,
$$

where $G(\Gamma)$ is the normalized distribution function.

The experimental points can be fitted by the method of moments [23]. Expanding $\exp (-\Gamma t)$ about $\bar{\Gamma}$, the autocorrelation function can be written :

$$
C(\mathbf{K}, t)=A \exp 2\left\{-\bar{\Gamma} t+\frac{1}{2} \mu_{2} t^{2}-\frac{1}{6} \mu_{3} t^{3}+\cdots\right\}+B,
$$


where $\bar{\Gamma}=\int G(\Gamma) \Gamma \mathrm{d} \Gamma$ is an averaged time constant which is related to the $z$-averaged translational diffusion coefficient by $D_{z}=\bar{\Gamma} / K^{2}$. The moments $\mu_{i}=\int(\Gamma-\bar{\Gamma})^{i} G(\Gamma) \mathrm{d} \Gamma$ characterize the non-exponential behaviour of the correlation function. The ratio $\mu_{2} / \bar{\Gamma}^{2}$ is a measure of the polydispersity of the sample. But for large polydispersities or broad distributions the analysis is no longer exact [24]. So, as a first step, we will use in this paper $\mu_{2} / \bar{\Gamma}^{2}$ only as a qualitative approach to the polydispersity, giving us an indication of the width of $G(\Gamma)$ which is related to the molecular weight distribution through $\Gamma=D K^{2}$ and $D \sim R_{\mathrm{H}}^{-1} \sim M^{-v}$.

Each experimental curve has been least-square fitted to a single exponential (Eq. (2)) and to a cumulant function (Eq. (7)) up to the third moment. The quality of the fit is estimated by the factor $Q$

$$
Q=1-\left|\sum_{i} \varepsilon_{i} \varepsilon_{i+1} / \sum_{i} \varepsilon_{i}^{2}\right|,
$$

$\varepsilon_{i}$ being the deviation of the $i$ th experimental point from the calculated value. If the $\varepsilon_{i}$ are randomly distributed, $Q$ is equal to one.

3. Experimental results. - 3.1 Solution in methanOL. - In methanol the highest concentration used is $0.54 \times 10^{-3} \mathrm{~g} / \mathrm{g}$.

Whatever theoretical function is used to fit the correlation function, $R_{\mathrm{H}}$ is found to be independent of the concentration and of the scattering angle over the full range studied $\left(30^{\circ} \leqslant \theta \leqslant 135^{\circ}\right)$.

From the values of $Q$ and $\mu_{2} / \bar{\Gamma}^{2}$ (Table II), it seems clear that the single exponential is not a very good fit and that our polymer sample has some polydispersity which is somewhat larger than the value given by the manufacturer. This apparent discrepancy could also be due to a very small amount of aggregates in our solution.

Let us now turn to the radius of gyration. If we take the only Mark-Houwink relation we are aware of for the PEO-methanol system [25].

$$
[\eta]=8.52 \times 10^{-2} M^{0.57} \mathrm{~cm}^{3} / \mathrm{g} \text { at } t=25^{\circ} \mathrm{C},
$$

and put it in the Flory-Fox relation [26] we obtain an approximate value for $R_{\mathrm{G}}$

$$
R_{\mathrm{G}}=\left[\frac{M[\eta]}{6^{3 / 2} \phi}\right]^{1 / 3}
$$

Table II. - Experimental parameters obtained by fitting autocorrelation function - PEO in methanol $-c=0.54 \times 10^{-3} \mathrm{~g} / \mathrm{g}$ and $0.40 \times 10^{-3} \mathrm{~g} / \mathrm{g}$.

\begin{tabular}{|c|c|c|}
\hline Fitting function & $A \exp (-2 \Gamma t)+B$ & $A \exp 2\left(-\bar{\Gamma} t+\mu_{2} \frac{t^{2}}{2 !}-\mu_{3} \frac{t^{3}}{3 !}\right)+B$ \\
\hline$D\left(\mathrm{~cm}^{2} / \mathrm{s}\right)$ & $(1.68 \pm 0.05) \cdot 10^{-7}$ & $(1.92 \pm 0.06) \cdot 10^{-7}$ \\
\hline$R_{\mathbf{H}}(\AA)$ & 230 & 200 \\
\hline$Q$ & 0.5 to 0.8 & 0.9 to 1 \\
\hline$\mu_{2} / \bar{\Gamma}^{2}$ & - & 0.3 to 0.46 \\
\hline
\end{tabular}


Taking $\phi=2.5 \times 10^{23}, R_{\mathrm{G}}=315 \AA$ is obtained for a molecular weight of 660000 . With the experimental value $R_{\mathrm{H}}=200 \AA$, the ratio $\rho=R_{\mathrm{G}} / R_{\mathrm{H}} \simeq 1.58$, which is, surprisingly, in fairly good agreement with theoretical predictions [27].

On the other hand, with this value of $R_{\mathrm{G}}, x=K R_{\mathrm{G}}<1$ over the entire range of diffusion angles and there is no contribution of internal motions to the correlation function.

We repeatedly measured the diffusion coefficient at the same concentration over a period of about two months. $D$ shows neither variation, nor evolution with time, thus showing the high stability of the PEO molecule in methanol. We can conclude that there is little, if any, aggregation of the PEO in methanol, confirming previous results [8], and that the molecule is quite stable.

3.2 IN TWICE DISTILLED, DEIONIZED WATER. - The concentration studied was $0.28 \times 10^{-3} \mathrm{~g} / \mathrm{g}$.

For all measurements the fit to equation (7) leads to a quality factor $Q>0.75$. The departure from the single exponential is considerably larger than in methanol, although decreasing with time. We can conclude from this that the "polydispersity " is higher in water than in methanol.

Figure 1 shows the variation of $\ln \left(\tau K^{2}\right)^{-1}$ with $\ln K$ for the same solution after times varying between two days and two months.

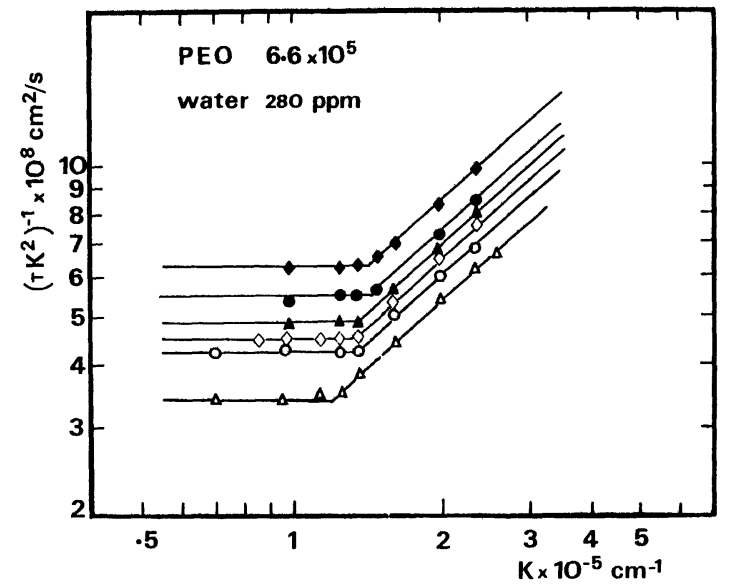

Fig. 1. $-\left(\tau K^{2}\right)^{-1}$ versus $K$. PEO $M_{\mathrm{w}}=660000, c=0.28 \times 10^{-3} \mathrm{~g} / \mathrm{g}$ in water. Age of the solution : $\triangle 2$ days; $\bigcirc 9$ days; $\diamond 18$ days; $\triangle 22$ days; 37 days; $\triangle 49$ days.

For the higher $K$ values, $\tau^{-1} \sim K^{w}$ where $w=2.94 \pm 0.02$. In that range, the $\tau^{-1}$ behaviour is in quite good agreement with the theoretical predictions [21] and with previous experimental results on polystyrene of very high molecular weight $\left(1\right.$ to $\left.2 \times 10^{7}\right)$ in benzene [28] $(w=2.85 \pm$ $0.05)$ or in trans-decalin [29] $(w=2.78)$.

For lower values of $K,\left(\tau K^{2}\right)^{-1}$ is constant and equal to the translation diffusion coefficient $D$. Assuming that Stokes law is valid, we can deduce from the values of $D$ the evolution of $R_{\mathrm{H}}$ with time, as reported in table III and plotted in figure 2 . This evolution is correctly described by a relation such as

$$
R_{\mathrm{H}}=R_{\mathrm{H} x}+\beta \exp (-\gamma t)
$$

$R_{\mathrm{H} x}=280 \AA$ represents the hydrodynamic radius $R_{\mathrm{H}}$ at the final state of the solution and depends solely on the molecular weight of individual molecules. $R_{\mathrm{H}}+\beta$ is the initial state depending on the molecular weight, on the concentration $c$ and in all likelihood on the history 
Table III. - Evolution of the parameters with time - PEO in water $-c=0.28 \times 10^{-3} \mathrm{~g} / \mathrm{g}$.

\begin{tabular}{|c|c|c|c|}
\hline Age (days) & $D \times 10^{8}\left(\mathrm{~cm}^{2} / \mathrm{s}\right)$ & $R_{\mathrm{H}}(\AA)$ & $\mu_{2} / \bar{\Gamma}^{2}$ \\
\hline 2 & 3.4 & 650 & 0.5 to 0.75 \\
9 & 4.25 & 530 & 0.5 to 0.7 \\
18 & 4.50 & 490 & 0.5 to 0.64 \\
22 & 4.85 & 460 & 0.5 to 0.6 \\
37 & 5.5 & 410 & 0.5 to 0.6 \\
49 & 6.2 & 380 & 0.5 to 0.6 \\
\hline
\end{tabular}

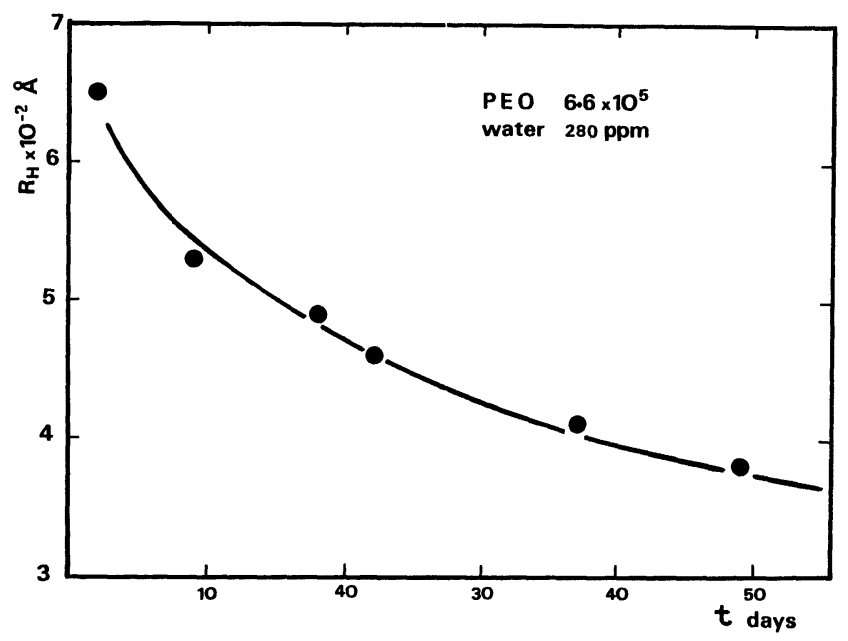

Fig. 2. $-R_{\mathrm{H}}$ versus $t$. Same solution as in figure 1 .

of the polymer. $\gamma$ describes the evolution with time and depends on $M, c$ and the nature of the solvent.

The Flory-Fox relation together with one of the Mark-Houwink formulae for PEO in water [30]

$$
[\eta]=1.25 \times 10^{-2} M^{0.78} \mathrm{~cm}^{3} / \mathrm{g}
$$

leads to $R_{\mathrm{G}}=430 \AA$ and $R_{\mathrm{G}} / R_{\mathrm{H}}=1.53$ for a $M_{\mathrm{w}}=660000$.

These results indicate that the degradation of the PEO with time could be, in fact, only a dissociation, the molecular weight of the initial aggregates being of the order of $2.5 \times 10^{6}$ or more if we assume $R_{\mathrm{G}} \sim M^{0.6}$. It may be worthwhile noting that the solution can be considered as dilute even with these high molecular weight particles, the concentration $c$ being of the order of $c_{\mathrm{s}}^{+} / 3$ in this case.

3.3 IN THE WATER-ISOPROPANOL MIXTURE (90/10). - The manufacturer recommends the adding of small amounts of ethanol or isopropanol in water to prevent sample degradation. We have studied such a solution, $10 \%$ of isopropanol being added to water.

The concentration used was $0.54 \times 10^{-3} \mathrm{~g} / \mathrm{g}$. 
Measurements gave a constant value for $\bar{\Gamma}$ over the entire range of scattering angles and over a forty days period, leading to

$$
D=(6.1 \pm 0.2) \cdot 10^{-8} \mathrm{~cm}^{2} / \mathrm{s},
$$

and

$$
R_{\mathrm{H}}=(280 \pm 10) \AA \text {. }
$$

In all cases $Q>0.75$ and $\mu_{2} / \bar{\Gamma}^{2} \simeq 0.3$, which is comparable with the values obtained for these factors with the solutions in methanol.

It is worthwhile noting that the hydrodynamic radius obtained in this case is very similar to the limiting value obtained in pure water. So, this would tend to prove that the action of isopropanol is a stabilization of the molecule, the associations which exist in pure water being hindered.

4. Conclusion. - Using a non destructive technique, we have shown that alcohols have a dispersing effect on PEO, which dissolved in this case into isolated molecules. On the other hand, in water, aggregates exist initially. The evolution with time is a disentanglement of the molecules, mechanical or chemical degradation being avoided. The ability to form aggregates depends probably on molecular weight. Here we have found that at a $M_{\mathrm{w}}=660000$, the initial aggregates could be formed by about four molecules. However this is by no means contradictory with the fact that a weight of $12 \times 10^{7}$ has been evaluated for the associated form of the PEO WSR $301\left(M_{\mathrm{w}} \simeq 3 \times 10^{6}\right)$ in pure water [31], which represents packs of about fifty molecules.

The study of the dependence on molecular weight and concentration of the dimension of the aggregates and of their evolution with time is currently taking place.

Such a phenomenon could have important consequences for the mechanical and rheological behaviour of these solutions. For example, the efficiency of PEO in drag-reduction may be enhanced by the presence of very high molecular weight structures such as networks in " dilute " solutions [17]. The addition of isopropanol or methanol as suggested by the manufacturer modifies the structure of the polymer in solution and changes the rheological properties of the solution and the efficiency of PEO in drag-reduction [18].

The kinetics of polymer dissolution is another important technological problem which could be related to this study.

Acknowledgments. - The authors are pleased to express their thanks to professor C. Wolff for valuable discussions and comments. We acknowledge partial financial support from the D.R.E.T.

\section{References}

[1] Wells, C. S., Ed., Viscous Drag Reduction (Plenum Press, New York) 1969.

[2] WolfF, C., Ed., Polymères et lubrificution (CNRS, Paris) 1975.

[3] Proceedings of conferences on Drag Reduction in Cumbridge (UK) (BHRA Fluid Engng, Cambridge) 1974 and 1977.

[4] Berman, N. S., Ann. Rev. Fluid Mech. 10 (1978) 47.

[5] Polymeric Drug Reduction, Proceedings of the symposium of the Society of Rheology, Boston 1980.

[6] Kalashnikov, V. N. and Kudin, A. M., Nature 242 (1973) 92.

[7] Cox, L. R., Dunlop, E. H. and North, A. M., Nature 249 (1974) 243.

[8] Carpenter, D. K., Santiago, G. and Hunt, A. H., J. Polym. Sci., Polym. Symp. 44 (1974) 75.

[9] Strazielle, C., Makromol. Chem. 119 (1968) 50. 
[10] (a) Cuniberti, C., Polymer 16 (1975) 306.

(b) Cuniberti, C. and Ferrando, R., Polymer 13 (1972) 380.

[11] Liu, K. J. and Parsons, J. L., Mucromolecules 1 (1968) 204.

[12] MAXFIeld, J. and ShePerd, I. W., Polymer 16 (1976) 505.

[13] White, A., Viscous Drag Reduction (Plenum Press, N.Y.) 1969, p. 293.

[14] GADD, G. E., Nuture 217 (1968) 1040.

[15] Laufer, Z., Jalink, H. L. and Staverman, A. J., J. Polym. Sci., Polym. Chem. Ed. 11 (1973) 3005.

[16] Dunlop, E. H. and Cox, L. R., Phys. Fluids 20 10(II) (1977) S 203.

[17] Hinch, E. J. and Elata, C., J.N.N. Fl. Mech. 5 (1979) 411.

[18] LAYEC-RAPHALEN, M. N., WolfF, C. and LAYEC, Y., unpublished results.

[19] (a) Weissberg, S. G., Simha, R. and Rothman, S., J. Res. Nut. Bur. Stund. 47 (1951) 298.

(b) Simha, R. and Utracki, L. A., Rheol. Actu. 12 (1973) 455.

[20] LAYEC, Y. and LAYEC-RAPHALEN, M. N., in preparation.

[21] De Gennes, P. G., Macromolecules 9 (1976) 587.

[22] Kapral, R., Ng, D. and Whittington, S. G., J. Chem. Phys. 64 (1976) 539.

[23] Koppel, D. E., J. Chem. Phys. 57 (1972) 4814.

[24] Brown, J. C., Pusey, P. N., Dietz, R., J. Chem. Phys. 62 (1975) 1136.

[25] Elias, H. G., Kunststoffe Plastics 4 (1961) 1.

[26] FlORY, P. J., Principles in polymer chemistry (Cornell Univ. Press, N.Y.) 1963.

[27] (a) Kirkwood, J. G. and Riseman, J., J. Chem. Phys. 16 (1948) 565.

(b) Yamakawa, H., Modern theory of polymer solutions (Harper and Row, N.Y.) 1971.

(c) Axcazu, A. Z., HaN, C. C., Macromolecules 12 (1979) 276.

[28] Adam, M. and Delsanti, M., Mucromolecules 10 (1977) 1229.

[29] Nose, T. and CHU, B., Mucromolecules 12 (1979) 1122.

[30] Bailey, F. E., Jr. and Koleske, J. V., P.olyethylene Oxide (Acad. Press) 1976.

[31] Wolff, C., Can. J. Chem. Eng. 58 (1980) 634.

[32] Allen, C., Booth, C., Hurst, S. J., Jones, M. N. and Price, C., Polymer 8 (1967) 391. 